\title{
Diagnosis and Treatment of Overactive Bladder
}

\author{
Howard A. Shaw ${ }^{1,2}$ and Julia A. Shaw ${ }^{2}$ \\ ${ }^{1}$ Hospital of Saint Raphael \\ ${ }^{2}$ Yale University School of Medicine \\ USA
}

\section{Introduction}

Overactive bladder $(\mathrm{OAB})$ is a disturbance of filling/storage and has been defined by the International Continence Society as "a symptom syndrome consisting of urgency with or without urge urinary incontinence, often associated with urinary frequency and nocturia." (Abrams et al., 2002) $\mathrm{OAB}$ has been divided into $\mathrm{OAB}$ without urinary incontinence $\left(\mathrm{OAB}_{\mathrm{dry}}\right)$ and $\mathrm{OAB}$ with urinary incontinence $\left(\mathrm{OAB}_{\mathrm{wet}}\right)$. The reported prevalence of $\mathrm{OAB}$ in women varies between 7.7 and 31.3\%, and increases with age. (Irwin et al., 2006a; McGother et al., 2006;Milsom, et al., 2001; Stewart et al., 2003; Wagg et al., 2007)

The symptoms of OAB include urinary urgency, urinary frequency, nocturia, and urinary urge incontinence. These symptoms often remain undetected and undertreated by both the woman and her providers, despite the substantial impact on a woman's quality of life. (Griffiths et al., 2006; Mardon et al., 2006) In a multiethnic survey, only 45 percent of women who reported weekly urinary incontinence sought care for their incontinence symptoms. (Harris et al., 2007) This leaves incontinent women with psychological morbidity and a diminished quality of life. (Irwin et al., 2006b)

\section{Etiology}

\subsection{Normal micturition}

The normal micturition cycle includes inhibition and contraction of detrusor smooth muscle, afferent signaling from the urothelium, contraction and relaxation of the smooth and striated sphincter muscles, and the central, peripheral, and autonomic nervous systems.

Urine storage occurs secondary to afferent signals stimulated by bladder filling. These afferent signals activate sympathetic pathways in the hypogastric and pudendal nerves, which lead to contraction of the smooth and striated sphincters, and at the same time inhibit detrusor contraction. In addition, high cortical centers are activated, (Griffiths et al, 2007), and stimulate the storage center in the pons. (Fowler et al, 2008) When further bladder filling leads to increased afferent signaling from the bladder, spinobulbospinal reflex pathways are carried via the pelvic nerve and spinal cord to the pontine micturition center, which activates parasympathetic pathways that cause bladder contraction and inhibit sympathetic and pudendal contraction of the sphincter (Fowler et al, 2008) 
For coordinated micturition to occur, parasympathetic stimulation of the detrusor occurs via cholinergic muscarinic receptors. Urethral smooth muscle contraction occurs chiefly by stimulation of alpha-adrenerigic receptors. (Fowler et al, 2008) In addition, a variety of neurotransmitter systems in the urothelial lining of the bladder and in bladder interstitial cells likely play a role in mediating bladder contraction and relaxation via afferent signaling. (Andersson, 2002) This complex interplay results in socially appropriate and effective voiding. Any disruption in this pathway can lead to storage and/or emptying disorders. Bladder overactivity may be related to neurogenic, myogenic, or idiopathic origins.

\subsection{OAB etiology}

The presumed etiology of $\mathrm{OAB}$ is uninhibited bladder contractions, but overactivity is not sufficient to cause incontinence (e.g. $\mathrm{OAB}_{\mathrm{dry}}$ ). In addition, leakage symptoms may be due to factors outside of the lower urinary tract such as failure of compensatory mechanisms in the lower urinary tract (e.g. fascial and muscular urethral support "hammock" that compresses the urethra when there is increased abdominal pressure or when the pelvic muscles are contracted), and functional impairments in some patients.

\subsubsection{Neurogenic etiologies}

\subsubsection{Suprapontine lesions}

Patients with suprapontine lesions such as cerebrovascular disease and Parkinson's disease can present with detrusor overactivity. These patients lose voluntary inhibition of micturition most likely secondary to uninhibited detrusor contractions. (Fall, et al, 1989) (Fall, et al, 1995) The cerebral cortex and the basal ganglia are theorized to suppress the micturition reflex. Therefore, damage to the brain results in bladder overactivity by reducing suprapontine inhibition. (Koelbl et al, 2009)

\subsubsection{Spinal cord lesions}

Spinal cord disruption below the level of the pons leads to unsustained and uncoordinated detrusor contractions. (Koelbl et al, 2009) Impairment or loss of bladder sensation usually occurs. Patients with spinal cord lesions above the lumbosacral level lose voluntary and supraspinal control of micturition. Bladder overactivity in these patients is mediated by spinal reflex pathways (deGroat et al, 1993) (Bros \& Comarr,1971)

\subsubsection{Non-neurogenic etiologies}

\subsubsection{Outflow obstruction}

Outflow obstruction is associated with detrusor overactivity. (Koelbl et al, 2009) Up to 50\% of patients with symptomatic benign prostatic enlargement exhibit bladder outlet obstruction. ( de Nunzio et al, 2003) However, OAB symptoms can occur independently of bladder outlet obstruction. One hypothesis that has been proposed to explain how outflow obstruction causes $\mathrm{OAB}$ and detrusor overactivity includes partial denervation.

Denervation injury has been shown to increase detrusor supersensitivity to acetylcholine. (Harrison et al, 1987) This may be the basis of unstable bladder activity. However, it is not clear how denervation develops in patients with outflow obstruction. It is possible that there 
is a reduction of blood flow due to increased intravesical pressure during voiding or the increased tissue pressure of hypertrophied bladder wall during filling. (Azadzoi et al, 1996) (Greenland \& Brading, 2001)

\subsubsection{Aging}

The prevalence of $\mathrm{OAB}$ in both men and women increases with age. In addition, storage symptom scores increase with age while bladder compliance decreases. (Koelbl et al, 2009) This implies that bladder function in both sexes has age related alterations. (Araki et al, 2003) There can be difficulty however, in determining in the elderly, the difference between neurogenic and non-neurogenic causes.

\subsubsection{Estrogen deficiency}

Menopause and estrogen deficiency have been implicated in the etiology of OAB symptoms. (Koelbl et al, 2009) Estrogen receptors (ERs) have been identified in the bladder and urethra. (Blakeman et al, 2000) The effect estrogen has on bladder contractility has yet to be elucidated.

However, it has been shown that estrogen replacement therapy can significantly improve the symptoms of frequency, urgency and urge incontinence. (Eriksen \& Rasmussen,1992) In addition, a metaanalysis of the effects of estrogen therapy on symptoms of OAB in postmenopausal women showed that estrogen therapy was associated with significant improvements in all symptoms of OAB. (Cardoza et al, 2004b) Thus it appears that menopause plays role in the development of bladder overactivity and OAB symptoms in women.

\subsubsection{Idiopathic etiologies}

Idiopathic detrusor overactivity is a diagnosis of exclusion of all other known causes. Mechanisms that have been proposed for idiopathic detrusor overactivity include myogenic, urothelial and muscarinic.

\subsubsection{Myogenic}

Mills et al, noted that denervation is consistently found in detrusor biopsies from patients with non-neurogenic detrusor overactivity. (Mills et al, 2000) They hypothesize that partial denervation of the detrusor alters the properties of smooth muscle, which leads to increased excitability and increased coupling between cells. Thus, myogenic changes in the bladder increase contractility locally.

\subsubsection{Urothelial}

Another mechanism that has garnered interest in idiopathic detrusor overactivity is the roles of the urothelium and suburothelial myofibroblasts in afferent activation. The C-fiber afferents have endings in the suburothelial layer of the bladder wall, and may reach the urothelium. (Koelbl et al, 2009) Upon bladder distention ATP has been shown to be released from the urothelium. (Ferguson et al, 1997) ATP receptors on afferent nerve terminals are stimulated by ATP release to evoke a neural discharge. It has been proposed that there is up-regulation of the afferent activation mechanisms(eg. an increased generation/release of ATP increased sensitivity of afferent nerves to mediators, increased number of afferent nerves) can cause the symptoms of OAB. (Koelbl et al, 2009) 


\subsubsection{Muscarinic}

As stated above, muscarinic receptors play a significant role in OAB. ATP, Acetylcholine (Ach) and other "signaling molecules, interact with the afferent nerve fibers under the urothelium. Bladder distention presumably causes release of Ach (and other molecules) to stimulate muscarinic receptors on myofibroblasts(predominantly M2). (Mansfield et al 2005) It appears that an increase in Ach release from the urothelium and/or upregulation of muscarinic receptors in the urothelium as well as in suburothelial myofibroblasts may increase afferent nerve activity and contribute to the development of detrusor overactivity. (Koelbl et al, 2009)

\section{Clinical presentation}

Women with $\mathrm{OAB}$ may experience urinary urgency at inconvenient and unpredictable times. Urgency is the complaint of a sudden compelling desire to pass urine which is difficult to defer. In addition, patients may experience increased 24-hour frequency defined as the total number of daytime voids and episodes of nocturia during a specified 24 hours period. Daytime frequency is defined as the number of voids recorded during waking hours and includes the last void before sleep and the first void after waking and rising in the morning. Both frequency and urgency may occur and urine leakage may occur prior to reaching a toilet. These symptoms interfere with work, activities of daily life, intimacy, and sexual function, and they can also cause embarrassment and diminished self-esteem. (Shaw \& Burrows, 2011) Many patients with OAB have symptoms that wake them up at night. Nocturia is the complaint that the individual has to wake at night one or more times to void.

\section{Diagnosis}

The presumptive diagnosis of $\mathrm{OAB}$ can usually be made in the primary care provider's office. Patients who present with the symptoms of urinary urgency and frequency can be evaluated utilizing standardized questionnaires, bladder diaries, a thorough history and physical examination, and simple laboratory tests. Those patients with more complex presentations may require urodynamic studies to confirm the diagnosis of $\mathrm{OAB}$ or detrusor overactivity.

\subsection{Symptom and quality of life questionnaires}

One of the most important aspects of the patient's history is to establish the impact of symptoms on their lives. This will guide the rest of the evaluation and subsequent treatment decisions. Most of the currently used symptom scales focus on patient-perceived frequency of symptoms and how much bother the symptoms cause. (Basra et al., 2007; Coyne et al., 2005a; Coyne et al., 2005b) Some newer validated scales have been developed which target more specific aspects of OAB. One of these, the $\mathrm{OAB}$ symptom score, is a 7-item questionnaire that records all the symptoms of $\mathrm{OAB}$ using consistent terminology. (Blaivas et al., 2007) Additionally, the International Continence Society (ICS) have established questionnaires (eg International Consultation on Incontinence Modular Questionnaire (ICIQ)) (Abrams et al, 2009)) 


\subsection{Bladder diaries}

Bladder diaries are an excellent tool that can be utilized to assess the frequency of daytime and nighttime voiding, as well as the timing of incontinence episodes and pad usage. Recently, bladder diaries have been developed that reliably assess the rate and severity of urinary urgency and are readily available. (Abrams et al, 2009) Despite some limitations, bladder diaries do provide a baseline with which to compare treatment efficacy.

\subsection{History}

A thorough history should inquire about the onset, duration, severity, and bother of lower urinary tract symptoms. In addition, a medical, surgical, gynecological, and obstetrical history should be obtained. Inquire about current medications which affect bladder function, particularly diuretics, alcohol, caffeine, narcotics, and calcium channel blockers.

\subsection{Physical Examination}

The physical examination should be focused on the abdominal and genitourinary examinations. The pelvic examination is used to evaluate the strength of the muscles of the pelvic floor and to assess for pelvic organ prolapse, urethral mobility, and stress urinary incontinence. The rectal examination is used to assess for any masses and to evaluate for constipation and anal tone. A simple, focused neurologic examination to evaluate pelvic reflexes, innervation of the lower extremities, and the patient's mental status completes the physical examination.

\subsection{Urinalysis}

Because some patients who present with acute symptoms of frequency and urgency have a urinary tract infection, a urinalysis (UA) is performed. In addition a UA will detect hematuria or glucosuria.

\subsection{Postvoid residual}

A post-void residual (PVR) is performed as a rough evaluation of as a measurement of the efficiency of evacuation of the bladder. This can be measured by bladder ultrasonography or post-void catheterization. Although there is no universally accepted definition of an abnormally elevated PVR, a high post-void residual (greater than $100 \mathrm{cc}$ ) may be cause for further, more complex testing. In addition, patients with high PVR's are at high risk for urinary retention, especially when anticholinergic medications are prescribed.

\subsection{Urodynamic studies}

Urodynamic studies can provide additional insight into bladder pathophysiology and can be a key to making the diagnosis of $\mathrm{OAB}$ and destrusor overactivity. Urodynamic studies are a series of clinical tests, such as flow studies, filling cystometry, pressure-flow studies and/or urethral function measurements. These can be combined with electromyography (EMG) recording and/or imaging by either X-rays or ultrasound. (Abrams et al, 2009) 
The goal of urodynamic studies is to reproduce the symptom(s) of the patient under controlled and measurable conditions. According to the $4^{\text {th }}$ International Consultation on Continence (Abrams et al, 2009) the role of urodynamic studies can be:

- To identify or to rule out factors contributing to the lower urinary tract(LUT) dysfunction To obtain information about other aspects of LUT dysfunction

- To predict the consequences of LUT dysfunction for the upper urinary tract

- To predict the outcome, including undesirable side effects, of a contemplated treatment

- To confirm the effects of intervention or understand the mode of action of a particular type of treatment

- To understand the reasons for failure of previous treatments for urinary incontinence, or for LUT dysfunction in general.

In addition to recommending the role of urodynamic studies, The International Continence Society (ICS) has provided standards for urodynamic terminology and techniques (Abrams, 2002) For example, urodynamic detrusor overactivity is defined by the ICS as "Loss of urine as a result incontinence of involuntary detrusor activity during the storage phase of urodynamic testing.

Following is a brief description of the most commonly used urodynamic studies.

\subsubsection{Uroflowometry}

Uroflowometry is a non-invasive measurement of urine flow rate. The patient urinates into a flow meter in private. (Schafer,2002) The flow rate is measured and displayed graphically. The volume voided, shape of the curve and the maximum flow rate are automatically graphed. These parameters determine if the patient is emptying their bladder normally. When an abnormal recording is obtained, it is best to repeat the assessment for reproducibility.

\subsubsection{Filling cystometry}

Filling cystometry is an invasive measurement of the pressure inside the bladder to assess its storage capabilities. It involves placing a pressure sensor into the bladder and another pressure sensor rectally or vaginally to measure abdominal pressure. A computer subtracts the abdominal pressure from the bladder pressure to provide the clinician with a graphic representation of pressure changes due to the true detrusor muscle. The bladder is usually filled with normal saline through the transurethral filling channel of a dual lumen catheter. The filling rate is usually controlled by a computer and the intravesical abdominal and detrusor pressure are monitored graphically. The storage ability of the bladder is assessed and presented graphically in terms of the volumes required to elicit various bladder sensations from the patient, its capacity, its compliance and its stability. The filling (storage) phase of cystometry is also the only method of demonstrating urodynamic stress incontinence (USI). (Abrams et al, 2009)

\subsubsection{Pressure-flow studies (Voiding cystometry)}

Voiding cystometry is a measurement of the mechanics of micturition. Generally this study is performed after bladder filling during cystometry is complete. While monitoring 
intravesical, abdominal and detrusor pressures, the patient is allowed to void and empties their bladder on a flow meter. Measurement of both flow rate and pressure allows voiding to be assessed. In patients whose bladder emptying is poor, it may determine if poor flow is due to outflow obstruction or poor detrusor contractility.

\subsubsection{Urethral pressure profilometry}

Urethral pressure profilometry is a test that measures the urethra's ability to maintain pressure along its length. This test is performed by placing a pressure sensor transurethrally into the bladder and usually withdrawing it along the urethra by a mechanical puller at a constant rate. The pressure along the length of the urethra is measured and graphically represented. The maximum pressure measured in the urethra gives an indication of the closure function of the urethra.

\subsubsection{Abdominal leak point pressure}

Similar to urethral pressure profilometry, abdominal leak point pressure is used as a measure of the urethra's ability to act as a valve to store urine. Intravesical or abdominal pressure is assessed while the patient is asked to increase their abdominal pressure by valsalva or by coughing. The abdominal pressure at which the patient leaks urine gives a measure of the closure pressure of the urethra. The greater the pressure required to produce leakage, the better the closure function of the urethra.

\section{Management}

The most commonly used measure of urinary incontinence (UI) treatment efficacy is a reduction in urinary incontinence episodes. Generally, this is recorded as the reduction in mean number of daily episodes, percent reduction from baseline, or reduction in leakage volume. Other outcome measures commonly used for $\mathrm{OAB}$ are urinary frequency (total number of daytime and nighttime voids) and frequency of urgency symptoms (with or without leakage). Cure is usually defined as complete absence of urinary incontinence. (Abrams, 2009)

One of the most important measures from the patient's perspective is quality of life. In the literature, many investigations measure patient perception of improvement of OAB, general satisfaction questions, and urinary incontinence-specific quality of life measures. The ICS recommends using patient reported outcome questionnaires that have been rigorously evaluated. (Koelbl et al, 2009)

\subsection{Conservative therapies}

Once the diagnosis of $\mathrm{OAB}$ has been made, the combination of dietary and lifestyle modification, bladder training, pelvic floor muscle training (PFMT), and biofeedback should be recommended as the initial intervention for OAB. (Burgio, 2002) The Agency for Health Care Policy and Research as well as the Third International Consultation on Incontinence recommends behavioral therapy as first-line therapy. (Wilson et al., 2005) The advantages of behavioral methods include avoidance of surgery, improved central control of bladder function and no adverse drug reactions. 


\subsubsection{Dietary and lifestyle modification}

A common sense approach to the treatment of patients with OAB should include counseling patients on dietary and lifestyle modification that may improve their symptoms and quality of life. In general, patients should increase awareness of amounts and types of fluids consumed, especially as it relates to their symptoms. Although not well studied some foods and beverages are believe to increase detrusor activity and symptoms of OAB. The authors recommend that patient's begin to eliminate one food or beverage at a time from the following list:

- $\quad$ Beverages

- Alcoholic

- Caffeinated (Coffee, Tea)

- Carbonated

- $\quad$ Foods

- Tomatoes and tomato-based products

- Spicy foods

- $\quad$ Citrus juice and fruits

- Artificial sweeteners

- Chocolate

- Corn syrup

- Sugar

- Honey

In one study patients with caffeine intake $>400 \mathrm{mg}$ / day were shown to be 2.4 times more likely to have detrusor overactivity. (Arya, et al., 2000) In addition, limiting fluid intake has been shown to reduce frequency and urgency as well as improve quality of life in patients with OAB. (Milne, 2008 and Swithinbank et al., 2005)

Although weight loss is a good lifestyle modification, in general, it has been shown to significantly improve only stress urinary incontinence symptoms, but not OAB symptoms. A large randomized trial of overweight and obese women with urinary incontinence symptoms underwent an intensive 6 month weight loss program compared to a group with a structured education program. (Subak et al., 2009) Mean weight loss was 8 percent $(7.8 \mathrm{~kg})$ and 1.6 percent $(1.5 \mathrm{~kg})$ in the intervention and control groups, respectively. The authors found that weekly incontinence episodes decreased by 47 percent in the intervention group compared to only 28 percent in the control group. Of note, is that these patients had a significant decrease in stress incontinence, but not urge incontinence episodes.

\subsubsection{Bladder retraining}

Bladder training involves patient education and scheduled voiding in which the voiding interval is progressively increased. This method is based upon frequent voluntary voiding which keeps the bladder volume low and training the central nervous system on pelvic floor musculature to inhibit urgency. Utilizing the patient's bladder diary, the initial frequency of timed voiding is based on the smallest time interval between voids. The goals of bladder training are to normalize urinary frequency, to improve control over bladder urgency, to increase bladder capacity, to decrease incontinence episodes, to prolong voiding intervals, 
and to improve the patient's confidence in bladder control. It is safe and may be beneficial. (Wallace et al., 2004) Bladder training requires compliant and motivated patients and may not be suitable for those with cognitive impairment. It can be time-consuming and is primarily effective during waking hours. (Ouslander et al., 2001)

Patients can be instructed to follow the steps listed below for bladder training :(Modified from DuBeau, 2011):

- Go to the toilet and try to pass urine every two hours while you are awake.

- You do not have to get up during the night!

- You must try to pass urine whether you feel the need or not

- You must try to pass urine even if you have just been incontinent.

- If you get a strong urge to go to the bathroom before your scheduled time:

- Stop, don't run to the bathroom!

- Stand still or sit down if you can.

- RELAX. Take a deep breath and let it out slowly.

- Concentrate on making the urge decrease or even go away, anyway you can.

- When you feel in control of your bladder, walk slowly to the bathroom, and then go.

- Keep this schedule until you can go two days without urine leakage.

- Then, increase the time between scheduled trips to the toilet by one hour

- When you can go two days without urine leakage, extend the time between trips again.

- Keep this up until you can go four hours between trips to the toilet, or until you are comfortable.

- This may take several weeks.

- DON'T GET DISCOURAGED! Bladder training takes time and effort, but it is an effective way to get rid of incontinence without medication or surgery

A review in 2009 found that bladder training may be helpful for the treatment of urinary incontinence, but definitive research is needed to support that conclusion. (Wallace et al., 2004) However, there is very little downside to this therapy.

\subsubsection{Pelvic floor muscle training (PFMT)}

PFMT involves exercises designed to improve the function of the pelvic floor muscles. Using PFMT to treat $\mathrm{OAB}$ is based on the theory that contraction of the levator ani muscles can reflexively inhibit contraction of the detrusor muscle. PFMT is defined as any program of repeated voluntary pelvic floor muscle contractions (VPFMC) taught by a trained healthcare professional. (Wilson et al., 2005) Patients are taught to squeeze the pelvic floor with three sets of 8 to 12 slow velocity contractions held for six to eight seconds each. These exercises should be performed at least three or four times a week and continued for at least 15 to 20 weeks. (Hay-Smith et al., 2009)

There is increasing evidence to support the use of PFMT for OAB. Patients with detrusor overactivity who completed a PFMT program experienced a clinically and statistically significant reduction in daily UI episodes. (Ba \& Berghmans, 2000 and Nygaard et al., 1996) These investigators also reported a significant decrease in urge score. This urge score was 
defined as the frequency of leakage ( $0=$ never to $4=$ always) during 9 activities that can trigger urge incontinence.

\subsubsection{Weighted vaginal cones}

Patients may have additional improvement in learning to appropriately do PFMT with the use of vaginal weighted cones. These cones are inserted in the vagina by the patient and she learns to contract the pelvic floor muscles to hold the cone in place.

\subsubsection{Biofeedback}

Biofeedback is used to teach patients how to control normal physiologic responses of the bladder and pelvic floor muscles that mediate urinary incontinence. Biofeedback for OAB consists of bladder-pressure biofeedback as well as the pelvic floor's muscular activity feedback. (Burgio et al., 1985)

\subsubsection{Limitations of behavioral therapy}

Behavioral therapy requires the active participation of motivated patients and a practitioner well-trained in behavioral therapy. Behavioral therapy does not cause permanent changes in bladder function; therefore, regular adherence and long-term compliance are needed for effectiveness.

\subsection{Pharmacological agents}

Traditionally, drug therapy is commenced at the same time as behavioral therapy. Drug treatment plays an important role in the management of women with $\mathrm{OAB}$, although many drugs currently in use have not been subjected to controlled clinical trials in the treatment of OAB. From a review of the literature, it is clear that there is no ideal drug. (Hay-Smith et al., 2005) Current pharmacological approaches to improving the treatment of OAB include delayed release formulations of existing oral agents, new pharmaceutical agents with greater specificity/selectivity, and alternative routes of administration. New generation pharmacological treatments provide better or comparable efficacy with fewer adverse drug events. (Shaw \& Burrows, 2011)

\subsubsection{Antimuscarinic (anticholinergic) drugs}

There are many different antimuscarinic compounds licensed for use for patients with OAB. Oxybutynin was the first drug of this class used specifically to treat the symptoms of OAB. This class of drugs has been considered the "gold standard" in the treatment of OAB for many years. However, there is little or no evidence to help clinicians choose between particular anticholinergic drugs. To add to the difficulty with studying this class of drugs, compliance with antimuscarinics is generally poor. (Brubaker et al., 2010)

Traditionally, it was thought that these drugs act by blocking the muscarinic receptors on the detrusor muscle. This resulted in decreased bladder contractions and thus reduced the symptoms of OAB. However, it appears that antimuscarinic drugs act primarily during the storage phase of the micturition cycle, decreasing urgency and increasing bladder capacity. 
During this phase, there is normally no parasympathetic input to the LUT. (Abrams \& Andersson, 2007)

A recent Cochrane review assessed the various anticholinergics available for the treatment of $\mathrm{OAB}$ in adults. The conclusions of this review were when the prescribing choice is between oral immediate-release oxybutynin and tolterodine, tolterodine might be preferred due to a reduced risk of dry mouth. In addition, they concluded that if extended-release preparations of either drug are available, they would be preferred to the immediate-release preparations because of the decreased risk of dry mouth and better compliance. There were insufficient data from trials of other anticholinergic drugs to draw any conclusions. (Hay-Smith et al., 2005) The most commonly prescribed anticholinergic drugs and their dosages in the treatment of OAB are listed in Table 1. (Shaw \& Burrows, 2011)

\subsubsection{Oxybutynin}

As mentioned above, oxybutynin was the first anticholinergic widely used for the treatment of OAB. It is an anticholinergic agent that has antimuscarinic, antispasmodic, and potential local anesthetic effects. Oxybutynin has been shown to have a high affinity for the M1 \& M3 receptors and much less affinity for the M2 receptor. (Hughes et al., 1992 and Nilvebrant \& Sparf, 1986) It is available in immediate release (IR), extended release (ER), transdermal patch and topical gel formulations. In general, the efficacy is similar for all formulations. The initial dosage for IR is $2.5 \mathrm{mg}$ two to three times daily, followed by titration as needed up to $20 \mathrm{mg} /$ day in divided doses. The ER formulation is started at $5 \mathrm{mg}$ once daily and titrated up to 20 to $30 \mathrm{mg}$ once daily.

The transdermal patch (equivalent to $3.9 \mathrm{mg} /$ day) applied to the abdomen, hip, or buttock is changed twice a week. The topical $10 \%$ gel is applied as $1 \mathrm{gm}$ (approximately $1 \mathrm{~mL}$ ) daily to the thigh, abdomen, upper arm, or shoulder. Currently, oxybutynin IR and ER are available as generic formulation in the United States. Oxybutynin IR is associated with high rates of anticholinergic adverse effects. Dry mouth is a particularly bothersome side effect for patients that can limit therapy with oxybutynin IR. This side affect is less frequent with the ER and transdermal preparations (Anderson et al., 1999; Davila et al., 2001; Versi et al., 2000) Irritation and pruritus at the application site has been reported in approximately 15 percent of patients using transdermal oxybutynin and 5 percent using the topical gel. (Dmochowski et al., 2002)

\subsubsection{Tolterodine}

Tolterodine has been shown to be a competitive muscarinic receptor antagonist with some selectivity for bladder muscarinic receptors [59]. It is available in immediate- and extendedrelease forms. Tolterodine is administered at 1 to $2 \mathrm{mg}$ twice a day for the IR preparation or 2 to $4 \mathrm{mg}$ per day using the ER preparation. It has similar efficacy when compared to other antimuscarinics. Both formulations have shown efficacy for symptoms of OAB in a large study population (Choo et al., 2008).

One of the few "head to head" studies between anticholinergic drugs was The STAR trial. In this study the investigators directly compared solifenacin (discussed below) at a flexible 5 or $10 \mathrm{mg}$ once daily dose with tolterodine extended release $4 \mathrm{mg}$ once daily in a randomized 
controlled trial. (Chapple et al., 2005) The authors found that the flexible dose of solifenacin showed marked advantages over the single dose of tolterodine extended release. In a reanalysis comparing only the patients in the trial taking solifenacin $5 \mathrm{mg}$ once daily with the patients in the tolterodine arm the authors found a more modest benefit. (Chapple et al., 2007) Solifenacin $5 \mathrm{mg}$ once daily was superior for incontinence episodes and pad usage, but showed no difference in urge incontinence or dryness rates. Notably in both analyses, the main advantage for solifenacin was minimizing rates of dry mouth and constipation. However, there were slightly more withdrawals due to adverse events in the solifenacin group.

\subsubsection{Solifenacin}

Solifenacin is an antimuscarinic agent has potent selectivity for the M3 over the M2 receptor. (Chapple et al., 2006) In addition it has a higher affinity for the M3 receptor in smooth muscle than it does for the M3 receptor in the salivary gland. (Chapple et al., 2006). This M3 selectivity provides for an improved side effect profile. Solifenacin is administered at 5-10 mg daily for the treatment of OAB.

It has been proven efficacious in multiple trials in patients with OAB. (Cardozo et al., 2004; Cardozo et al., 2008; Chapple, 2005) Another recent study confirmed that solifenacin was significantly more effective in reducing the mean number of severe urgency episodes with or without incontinence per 24 hours, improved urgency symptoms and was well tolerated. Additionally, no cognitive impairment has been associated with this drug. (Kay et al., 2006)

\subsubsection{Trospium chloride}

Trospium chloride is a quaternary ammonium compound that is nonselective for the muscarinic receptor. It also has smooth muscle relaxant qualities. (Staskin et al., 2007) Trospium chloride is available in an IR formulation given $20 \mathrm{mg}$ twice daily or an ER formula administered $60 \mathrm{mg}$ daily. The uniqueness of this antimuscarinic is that it is renally cleared. Care should be used in the elderly and patients with renal impairment. The initial dosing in these patients she be the IR formulation $20 \mathrm{mg}$ once daily. The ER formulation should not be used in patients with severe renal impairment. Because of poor bioavailability, trospium chloride must be taken on an empty stomach.

When compared to placebo, trospium chloride showed a greater decrease in the number of daily episodes of incontinence than patients who received placebo (from a mean of 2.9 to 1.0 with trospium and 1.6 with placebo). (Zinner et al., 2004) Side effects in the trospium chloride group included dry mouth (20 percent) and constipation (11 percent).

In a randomized trial utilizing the ER formulation (60 $\mathrm{mg}$ once daily) for patients with severe urge incontinence, patients' incontinence episodes decreased significantly compared to placebo. Adverse events were lower than reported for immediate-release trospium chloride (dry mouth 13 percent, constipation 8 percent). (Dmochowski et al., 2008)

\subsubsection{Fesoterodine}

Fesoterodine is given at a starting dose of $4 \mathrm{mg}$ once daily, which can be increased to $8 \mathrm{mg}$. As with most of the anticholinergic drugs, the most common side effects are dry mouth and constipation. 
Fesoterodine is metabolized to 5-hydroxymethyl tolterodine, (the active metabolite of tolterodine).

\subsubsection{Darifenacin}

Similar to solifenacin, the newer antimuscarinic drug darifenacin is more selective for M-3 muscarinic receptors in the bladder. Drifenacin is administered $7.5 \mathrm{mg}$ daily and can be increased to $15 \mathrm{mg}$ daily. In a randomized trial of darifenacin versus placebo, median incontinence episodes were show to significantly decrease with darifenacin. (Zinner et al., 2006) However, dry mouth and constipation rates were similar when compared to other anticholinergics (29\% dry mouth and $18 \%$ constipation).

As noted above, the most common side effects associated with darifenacin are mild to moderate dry mouth and constipation. This drug has been studied in patients who were dissatisfied with prior OAB treatment with oxybutynin ER or tolterodine ER. The authors found significant improvements in OAB symptoms with darifenacin. (Zinner et al., 2008) Additionally, long-term studies have shown persistence of continuation with darifenacin therapy and well-maintained treatment benefits (over 2 years in duration). (Haab et al., 2006 \& Hill et al., 2007)

Because of its' selectivity for the M3 receptor darifenacin minimizes the risk of side effects due to blockade of other muscarinic subtypes, such as M1 mediated cognitive impairment. (Foote et al., 2005) This is important in relation to the treatment of elderly populations who may be more susceptible to cognitive impairment and CNS effects.

\begin{tabular}{|l|l|l|}
\hline Generic name & Brand Name & Dosage \& Administration \\
\hline Darifenacin hydrombromide & Enablex & 7.5 to 15 mg daily \\
\hline Fesoterodine & Toviaz & $4 \mathrm{mg}$ daily, can be increased to 8 mg daily \\
\hline Oxybutynin extended release & Ditropan XL & $5 \mathrm{mg}$ daily, titrate up to 20-30 mg daily \\
\hline Oxybutynin gel & Gelnique & $\begin{array}{l}\text { Topical 10\% gel applied as 1 g daily to } \\
\text { thigh, abdomen, upper arm or shoulder }\end{array}$ \\
\hline $\begin{array}{l}\text { Oxybutynin immediate } \\
\text { release }\end{array}$ & Ditropan & $\begin{array}{l}2.5 \mathrm{mg} \text { 2-3 times daily, followed by } \\
\text { titration as needed u to 20 mg/d in } \\
\text { divided doses }\end{array}$ \\
\hline Oxybutynin transdermal & Oxytrol & $\begin{array}{l}\text { Applied to abdomen, hip or buttock and } \\
\text { changed twice per week (equivalent to 3.9 } \\
\text { mg/d) }\end{array}$ \\
\hline Solifenacin succinate & Vesicare & $5-10 \mathrm{mg}$ daily \\
\hline $\begin{array}{l}\text { Tolterodine tartrate extended } \\
\text { release }\end{array}$ & Detrol LA & $2-4 \mathrm{mg}$ daily \\
\hline $\begin{array}{l}\text { Tolterodine tartrate } \\
\text { immediate release }\end{array}$ & Detrol & $1-2 \mathrm{mg}$ twice daily \\
\hline $\begin{array}{l}\text { Trospium chloride extended } \\
\text { release }\end{array}$ & Sanctura & $60 \mathrm{mg}$ daily \\
\hline $\begin{array}{l}\text { Trospium chloride immediate } \\
\text { release }\end{array}$ & Sanctura & $20 \mathrm{mg}$ twice daily \\
\hline
\end{tabular}

Table 1. Commonly prescribed anticholinergic drugs for treatment of OAB 


\subsubsection{Antidepressants}

\subsubsection{Duloxetine}

Duloxetine is a serotonin noradrenaline re-uptake inhibitor that is approved by the Food and Drug Administration (FDA) for depression, but not for urinary incontinence. The mechanism of action is to significantly increase sphincteric muscle activity during the filling/storage phase of micturition. Although not approved for use in patients with OAB symptoms alone, it may have some efficacy. Steers et al (Steers et al., 2007) randomized 306 women to placebo or duloxetine over 12 weeks. Duloxetine showed significant benefit in 24hour urinary frequency and incontinence episodes. It also improved condition-specific quality of life measures. However, no significant increase was observed in mean voided volume, suggesting that the benefits were mediated through an effect at the urethral rhabdosphincter, rather than any direct effect on detrusor contractility. Thus, duloxetine may be considered as an option for patients who cannot tolerate antimuscarinic drugs. However, duloxetine's primary efficacy is in the treatment of stress urinary incontinence.

\subsubsection{Imipramine}

Imipramine, an antidepressant, is the only drug in this category that has been widely used to treat the symptoms of OAB. It has multiple pharmacological effects, including systemic antimuscarinic actions and blockade of the reuptake of serotonin and noradrenaline, but its mode of action in the treatment of $\mathrm{OAB}$ is not clear. (Hunsballe \& Djurhuus, 2001) Imipramine has shown a favorable therapeutic effect in the treatment of nocturnal enuresis in children with a success rate of $10-70 \%$ in controlled trials. (Glazener et al., 2003; Hunsballe \& Djurhuus, 2001) However, there are no good quality randomized trials that prove the efficacy of imipramine in the treatment of OAB.

\subsubsection{Intravesical botulinum toxin}

Botulinum toxin is a neurotoxin that inhibits the release of acetylcholine from presynaptic cholinergic nerve endings. This inhibition results in a localized reversible chemical denervation, with decreased detrusor contractility. Although it is currently not FDAapproved for the treatment of $\mathrm{OAB}$, it shows promise as an addition to the treatment arsenal. The most likely place for its use is for patients who fail oral therapies. Current data primarily address only patients with refractory detrusor overactivity. In the most recent Cochrane review, randomized trials of intravesical botulinum versus placebo reported results favoring botulinum toxin. (Duthie et al., 2007) The authors noted that there was significant improvement in incontinence episodes, bladder capacity, maximum detrusor pressure and quality of life. They concluded "Botulinum toxin injections into the bladder appeared to give few side effects or complications, but there were no long-term follow-up studies, and there could be rare side effects that have not been discovered yet." (Duthie et al., 2007)

As stated above, many questions remain regarding its use, including the optimal dose and site of injection, the appropriate population, and long-term safety. To address this issue, Schurch et al (Schurch et al., 2007) randomized 59 patients with neurogenic detrusor overactivity to intravesical botulinum A (200 or $300 \mathrm{U}$ ) or placebo. These investigators noted significant improvements when compared to placebo using the Incontinence Quality of Life 
Questionnaire. They did not discover clear differences between the two doses. Intravesical botulinum toxin has a variable duration of action, with loss of efficacy typically seen within one year. (Reitz et al., 2007) Based upon this limited data, it appears that there may be a role for the use of intravesical botulinum for patients with $\mathrm{OAB}$, especially when other therapies fail. Finally, one of the bothersome adverse effects is urinary retention which can last up to three months after one injection. This, the clinician must have considerable knowledge and skill in the judicious use of botulinum toxin.

In a recent literature review (Anger et al, 2010) the authors systematically reviewed the efficacy and safety of botulinum toxin in the management of overactive bladder. Based upon this review of three small randomized placebo controlled trials they found that patients treated with botulinum toxin-A had 3.88 fewer incontinence episodes per day (95\% CI -6.15, -1.62). Patients also noted significant improvements in quality of life compared with placebo. In addition they found a 9-fold increased odds of increased post-void residual after botulinum toxin-A compared with placebo $(8.55 ; 95 \%$ CI 3.22, 22.71). They concluded that "intravesical injection of botulinum toxin resulted in improvement in medication refractory overactive bladder symptoms".

\subsubsection{Combination therapies}

Since most patients do not achieve complete continence with behavioral therapy or anticholinergic therapies alone, many clinicians combine these two in the treatment of OAB. A combination of anticholinergic agents and behavioral interventions have been shown to be safe and effective in many studies. (Fantl et al., 1996; Gormley, 2002; Milne \& Moore, 2006) Side affect profiles of most of the drugs used for OAB make long term adherence to therapy difficult.

In a large study, Mattiasson et al (Mattiasson et al., 2003) showed additional benefit from bladder retraining when compared with tolterodine alone. Additionally, $76 \%$ of the patients on tolterodine and behavioral therapy noted improvement in their bladder symptoms compared to baseline as compared with $71 \%$ in the tolterodine group (Mattiasson et al., 2003)

Combination therapy has been shown to be associated with significantly fewer incontinent episodes, an improved quality of life, and greater treatment satisfaction when compared to non-pharmacologic intervention alone or drug treatment alone. (Wyman et al., 1998) However, the authors found that the effects of each of the interventions were similar 3 months after treatment. They concluded that the nature of the treatment may not be as important as having a structured intervention program that includes education, counseling, and frequent monitoring of the treatment. (Wyman et al., 1998)

Finally, Chancellor et al ( Chancellor et al., 2008), in a more recent trial, compared the benefits of anticholinergic therapy alone against a combination of anticholinergic and behavioral therapy in 395 patients in a randomized controlled trial of flexible dose darifenacin ( $7.5 \mathrm{mg}$ /day increased to $15 \mathrm{mg}$ /day if required), with or without additional advice about dietary modification, timed voiding/bladder retraining, and pelvic floor training. No significant differences were observed between groups in OAB symptoms. 


\subsection{Neuromodulation}

Neuromodulation can be utilized to increase pelvic muscle contraction and decrease detrusor contractions. The use of neuromodulation is assumes that $\mathrm{OAB}$ results from an imbalance of inhibitory and excitatory control systems of the detrusor that leads to the symptoms of OAB during the filling phase. (Fall and Lindstrom ,1991) Neuromodulation is gaining popularity because it bridges the gap between conservative treatments and highly invasive options. Currently, the methods used include sacral nerve modulation (SNM) via surgically implanted electrodes and other newer methods that deliver percutaneous stimulation of the peripheral tibial nerve.

The exact mechanism of action for neuromodulation is not well understood. However, many theories have been proposed as follows. (Al-Shaiji et al, 2011)

- Sensory input through the pudendal nerve has been shown to inhibit detrusor activity. Pudendal nerve stimulation and enhancement of external sphincter tone may serve to control bladder overactivity and facilitate urine storage. (Vodusek et al, 1986)

- The bladder responds to neural stimulation initially with rapid contraction. This is then followed by slow, longer-lasting relaxation. With recurrent, repetitive electrical stimulation, there is a downregulation of the bladder's response, thus reducing the detrusor muscle overactivity. (Appell \& Boone, 2007)

- Stimulation of afferent sacral nerves in the pelvis or lower extremities has been shown to increase the inhibitory stimuli to the efferent pelvic nerve thus reducing detrusor contractility. (Fall \& Lindstrom, 1991)

- Neuromodulation affects the "neuroaxis" at various levels and restores the balance between excitatory and inhibitory regulation at various locations within the peripheral and central nervous system. (Van Der Pal, 2006)

\subsubsection{Noninvasive electrical stimulation}

There are several devices on the market to provide noninvasive electrical stimulation to the pelvic floor. The removable device is placed in the. Its mechanism of action in the treatment of $\mathrm{OAB}$ is thought to be secondary to reflex inhibition of the detrusor muscle by stimulation of the pudendal nerve. There is some evidence that this therapy has some efficacy in the treatment of OAB. (Berghmans et al., 2000; Goode et al., 2003)

\subsubsection{Sacral neuromodulation (SNM)}

SNM uses mild electrical pulses to stimulate the sacral nerves that innervate the pelvic floor and lower urinary tract. InterStimTM therapy was developed by Medtronic (Minneapolis, Minn, USA) for use in humans. This technology utilizes an implanted unilateral lead stimulating the S3 nerve root. This electrode is attached to a small pacemaker placed within a subdermal pocket in the buttock region. It is FDA approved for refractory urge incontinence, refractory urgency frequency, and idiopathic nonobstructive urinary retention. "Off-label uses of the technology include for treatment of interstitial cystitis and pelvic pain syndrome. (Al-Shaiji et al, 2011)

Implantation of the device usually proceeds in 2 steps: a test phase and implantation or lead removal based on test response. The initial test phase can be performed in the office or 
operating room allowing for placement of the lead with a test period of 1 to 2 weeks; full implantation can be performed under local or general anesthesia. Response is objectively evaluated by pre- and postvoiding diaries assessing various urinary parameters.

The test phase of the procedure consists of implantation of tined quadripolar leads, under intravenous (IV) sedation, local anaesthesia, or general anaesthesia. Under fluoroscopy with a C-arm the right or left S3 foramen is identified and the permanent tined lead is passed through the foramen needle. The lead is then tested for a response. Correct placement in the S3 foramina includes bellows contraction of the pelvic floor and plantar flexion of the great toe. Once the appropriate side and position is selected, the lead is connected to an external pulse generator and taped to the skin surface. A 7- to 14-day home test period is used to determine which patients meet criteria to have the IPG implanted. Patients who respond favorably and demonstrate a 50\% symptom improvement from baseline have the permanent generator implanted. (Al-Shaiji et al, 2011)

The most common adverse events include lead migration, implant site pain, bowel dysfunction, and infection. Infection usually resolves with antibiotics and the lead adverse events can usually be corrected by reprogramming, reinforcing the lead, or inserting a new lead contralaterally.

There is now convincing evidence for the success of SNM for refractory OAB. Several studies including RCTs and long-term observational studies reported fair clinical response between 64 and $88 \%$ of all patients (Leong et al, 2010).

\subsubsection{Percutaneous stimulation of the tibial nerve}

In addition, percutaneous stimulation of the tibial nerve (PTNS) has shown promise in the treatment of patients with refractory urge incontinence. PTNS is a minimally invasive, office-based procedure that involves percutaneous placement of a 34-gauge (ga) needle over the medial malleolus of the ankle to provide stimulation of the posterior tibial nerve. The procedure is repeated in 30-minute treatment sessions over a period of 12 weeks. PTNS in patients with $\mathrm{OAB}$ has been shown to significantly reduce in symptoms and improvement in health-related quality of life. (Yoong et al, 2010) However, one multicenter randomized trial of 100 patients with OAB symptoms did not show a reduced rate of urinary frequency when PTNS was compared to tolterodine extended release, $4 \mathrm{mg}$ daily. (Peters, 2009)

\subsection{Surgery}

In general most patients with OAB symptoms can be treated with medical and behavioral therapies. Generally, augmentation cystoplasty is only considered when patients have small volume bladders and are debilitated by their symptoms.

\subsubsection{Augmentation cystoplasty}

Augmentation cystoplasty (AC) is a surgery where a portion of the bowel is removed and patched to the bisected bladder. This procedure increases bladder capacity and decreases bladder pressure caused by unstable detrusor contractions. Considered a procedure of last resort, the risks of the surgery include recurrent UTI's, renal or bladder infections, metabolic changes and mucus production. (Khastgir et al., 2003) reviewed outcomes associated with 
augmentation cystoplasty. This group emphasized clinical outcomes (e.g. maximum detrusor pressure and bladder volume capacity) and patient symptoms (e.g. incontinence episodes and number of pads). Other outcomes included a questionnaire that measured quality of life, and the evaluation of complications from the surgery.

Using a definition of success as a $\geq 50 \%$ reduction in symptoms, one group found a $97 \%$ success rate for AC. (Blaivas et al., 2005)

\subsection{Future therapies}

\subsubsection{Beta adrenoreceptor agonists}

The human detrusor muscle contains $\mathrm{B}_{2}$ and $\mathrm{B}_{3}$-adrenoceptors. Both receptors are thought to be involved in detrusor relaxation. Currently, there are a number of [beta] 3-adrenoceptor selective agonists being evaluated as potential treatment for OAB, including YM178 (mirabegron). Chapple et al (Chapple et al., 2008) conducted a clinical trial with mirabegron versus tolterodine and placebo in patients with OAB. Patients in the treatment arm had a statistically significant reduction in mean micturition frequency when compared to placebo. In addition, mirabegron was superior to placebo in regard to mean volume voided per micturition, mean number of incontinence episodes, nocturia episodes, urgency incontinence episodes, and urgency episodes per 24 hours. The drug was well tolerated, and the most commonly reported adverse effects were headache and gastrointestinal adverse effects. Further randomized trials will be needed to prove efficacy.

\subsubsection{Centrally acting drugs}

\subsubsection{Tramadol}

Many parts of the brain are activated during storage and voiding and there is increasing interest in centrally acting drugs which modulate the micturition reflex. (Andersson \& Pehrson, 2003) Tramadol is an analgesic that is a weak $\mu$-receptor agonist; however, it is metabolized to several different compounds, which inhibit serotonin (5-HT) and noradrenaline reuptake. (Grond \& Sablotzki, 2004;Safarinejad \& Hosseini, 2006) Both $\mu$ receptor agonist and amine reuptake inhibition are useful in the treatment of OAB. In a double-blind, placebo-controlled, randomized study, 76 patients were given $100 \mathrm{mg}$ tramadol sustained release every 12 hours for 12 weeks. Tramadol significantly reduced the number of incontinence periods by $50 \%$ per 24 hours. The authors concluded that tramadol provided beneficial clinical and urodynamic effects.

\subsubsection{Tachykinins}

Tachykinins such as substance $\mathrm{P}$, neurokinin A (NKA), and neurokinin B (NKB) may play a role in OAB. Substance P has a specific receptor (NK1) that is expressed in the dorsal horn of the spinal cord and may play an important role in detrusor overactivity. (Grond \& Sablotzki, 2004; Safarinejad \& Hosseini, 2006)

Aprepitant, an NK1 receptor antagonist, has been shown to significantly improve symptoms of $\mathrm{OAB}$ in postmenopausal women with a history of urgency incontinence or mixed incontinence in a small pilot. (Green et al., 2006) Aprepitant significantly decreased the average daily number of micturitions $(-1.3 \pm 1.9)$ compared with placebo $(-0.4 \pm 1.7)$. The 
average daily number of urgency episodes was significantly reduced, as were the average daily number of urgency incontinence and total urinary incontinence episodes. The authors concluded that NK1 receptor antagonism holds promise as a potential treatment approach for OAB.

\section{Summary}

Overactive bladder $(\mathrm{OAB})$ is a common medical condition, yet often undetected and undertreated despite the substantial impact on a woman's quality of life. The etiology of $\mathrm{OAB}$ is unclear, but several mechanisms may interplay and interconnected in contributing to the multi-symptom condition. Despite symptoms that often interfere with work, daily life, intimacy, and also cause embarrassment and diminished self-esteem, less than half of sufferers seek treatment from a licensed provider.

A working clinical diagnosis of $\mathrm{OAB}$ can usually be made simply by utilizing proper urinary questionnaires, urinary diaries or a thorough medical history and physical examination. Confirmation of diagnosis is most often achieved via a post-void residual, simply cystometry or multichannel urodynamic testing.

The primary goal of treatment of $\mathrm{OAB}$ is simply a reduction in urinary incontinence episodes. First-line therapy for $\mathrm{OAB}$ should include conservative options such as timed voiding and alterations in types and amount of fluid intake. Counseling patients on dietary and lifestyle modification will often improve their acute symptoms and decrease the number of voiding episodes per day. Other non surgical first line options include pelvic floor muscle training and/or biofeedback, both of which center around exercises designed to improve the function of the pelvic floor muscles. The primary limitations of behavioral therapy is the required long term patient commitment required for effectiveness.

Antimuscarinic (anticholinergic) drugs are the cornerstone of pharmacological treatment of $\mathrm{OAB}$ and provide a favorable efficacy/tolerability/safety profile. These result in decreased bladder contractions and thus reduced the symptoms of OAB. For patients who are not candidates for antimuscarinic (anticholinergic) therapy or have failed previous trials of other medical therapy, noninvasive electrical stimulation to the pelvic floor via neuromodulation may increase pelvic muscle contractions and decrease detrusor contractions. More aggressive nerve modulation and stimulation therapies include, sacral nerve stimulation or peripheral nerve stimulation, which can be considered in patients with refractory urge incontinence. Lastly, surgical options, including augmentation cystoplasty and detrusor myectomy have been developed for those in which all other treatment alternatives have been exhausted.

Lastly, there are promising new receptor-specific medical alternatives emerging and future studies will determine their place in the therapeutic arsenal.

Despite the prevalence of $\mathrm{OAB}$, and the patients' lack of willingness to report their life altering symptoms, screening for $\mathrm{OAB}$ should be part of every woman's annual well woman visit. Health care providers need not shy away from urinary incontinence questionnaires, as straightforward diagnosis and $\mathrm{OAB}$ treatments are available. Although the primary treatment goal of $\mathrm{OAB}$ is the reduction in urinary incontinence episodes, to the patient, the most important measure is quality of life. 


\section{References}

Abrams P, Cardozo L, Fall M, et al; Standardisation Sub-committee of the International Continence Society. The standardisation of terminology of lower urinary tract function: report from the Standardisation Sub-committee of the International Continence Society. Neurourol Urodyn 2002;21:167-178.

Abrams P, Andersson KE. Muscarinic receptor antagonists for overactive bladder. BJU Int 2007;100:987-1006.

Al-Shaiji TF, Banakhar M, Hassouna MM. Pelvic Electrical Neuromodulation for the Treatment of Overactive Bladder Symptoms. Advances in Urology. Volume 2011, Article ID 757454, 7 pages. doi:10.1155/2011/757454

Anderson RU, Mobley D, Blank B, et al. Once daily controlled versus immediate release oxybutynin chloride for urge urinary incontinence. OROS Oxybutynin Study Group. J Urol 1999; 161:1809.

Anderson KE. Potential benefits of Muscarinic M3 receptor selectivity," European Urology Supplements, vol. 1, no. 4, pp. 23-28, 2002.

Andersson KE. Bladder activation: afferent mechanisms. Urology 2002; 59:43.

Andersson KE, Pehrson R. CNS involvement in overactive bladder: pathophysiology and opportunities for pharmacological intervention. Drugs 2003;63:2595-2611.

Andersson KE, Wein AJ. Pharmacology of the lower urinary tract: basis for current and future treatments of urinary incontinence. Pharmacol Rev 2004;56:581-631.

Andersson KE. LUTS treatment: future treatment options. Neurourol Urodyn 2007;26(6 suppl):934-947

Appell R, Boone TB. Surgical management of overactive bladder, Current Bladder Dysfunction Reports, vol. 2, pp. 37-45, 2007.

Arya LA, Myers DL, and Jackson ND. Dietary caffeine intake and the risk for detrusor instability: a case-control study. Obstetrics and Gynecology, vol. 96, no. 1, pp. 8589, 2000.

Anger JT, Weinberg A, Suttorp MJ, Litwin, MS, Shekelle PG. Outcomes of intravesical botulinum toxin for idiopathic overactive bladder symptoms: a systematic review. Journal of Urology. 183(6):2258-2264, June 2010.

Araki, I., et al., Lower urinary tract symptoms in men and women without underlying disease causing micturition disorder: a cross-sectional study assessing the natural history of bladder function. J Urol, 2003. 170(5): p. 1901-4.

Azadzoi, K.M., et al., Canine bladder blood flow and oxygenation: changes induced by filling, contraction and outlet obstruction. J Urol, 1996. 155(4): p. 1459-65.

Basra R, Artibani W, Cardozo L, et al. Design and validation of a new screening instrument for lower urinary tract dysfunction: the bladder control self-assessment questionnaire (B-SAQ). Eur Urol 2007;52:230-237.

Berghmans LC, Hendriks HJ, De Bie RA, et al. Conservative treatment of urge urinary incontinence in women: a systematic review of randomized clinical trials. BJU Int 2000; 85:254.

Blakeman PJ, Hilton P,Bulmer JN. Oestrogen and progesterone receptor expression in the female lower urinary tract, with reference to oestrogen status. BJU Int, 2000.86(1): p. 32-8.

Bo K, Berghmans LCM. Nonpharmacologic treatments for overactive bladder-pelvic floor exercises. Urology, vol. 55, no. 5, supplement 1, pp. 7-11, 2000. 
Bogart LM, Berry SH, Clemens JQ. Symptoms of interstitial cystitis, painful bladder syndrome and similar diseases in women: a systematic review. J Urol 2007; 177:450.

Blaivas JG, Weiss JP, Desai P, Flisser AJ, Stember DS, Stahl PJ: Longterm followup of augmentation enterocystoplasty and continent diversion in patients with benign disease. The Journal of urology 2005, 173(5):1631-1634.

Blaivas JG, Panagopoulos G, Weiss JP, et al. Validation of the overactive bladder symptom score. J Urol 2007;178:543-547; discussion 547.

Bros E, ComarrAE. Physiology of Micturition, Its Neurological Disorders and Sequelae. 1971, Baltimore: University Park Press.

Brubaker L, Fanning K, Goldberg EL, et al. Predictors of discontinuing overactive bladder medications. BJU Int 2010;105:1283-1290.

Burgio KL, Whitehead WE, Engel BT. Urinary incontinence in the elderly. Bladder-sphincter biofeedback and toileting skills training. Ann Intern Med 1985;103:507-515.

Burgio KL. Influence of behavior modification on overactive bladder. Urology 2002;60(5 suppl 1):72-76; discussion 77.

Campbell JD, Gries KS, Watanabe JH, Ravelo A, Dmochowski RR, Sullivan SD. Treatment success for overactive bladder with urinary urge incontinence refractory to oral antimuscarinics: a review of published evidence. BMC Urology 2009, 9:18.

Cardozo L, Lisec M, Millard R, et al. Randomized, double-blind placebo controlled trial of the once daily antimuscarinic agent solifenacin succinate in patients with overactive bladder. Journal of Urology, vol. 172, no. 5, part 1, pp. 1919-1924, 2004.

Cardozo, L., et al., A systematic review of the effects of estrogens for symptoms suggestive of overactive bladder. Acta Obstet Gynecol Scand, 2004. 83(10): p. 892-7.

Cardozo L, Hessdorfer E, Milani R, et al. Solifenacin in the treatment of urgency and other symptoms of overactive bladder: results from a randomized, double-blind, placebocontrolled, rising-dose trial. BJU International, vol. 102, no. 9, pp. 11201127, 2008.

Chapple CR, Martinez-Garcia R, Selvaggi L, et al; for the STAR study group. A comparison of the efficacy and tolerability of solifenacin succinate and extended release tolterodine at treating overactive bladder syndrome: results of the STAR trial. Eur Urol 2005;48:464-470.

Chapple CR, Cardozo L, Steers WD, Govier FE. Solifenacin significantly improves all symptoms of overactive bladder syndrome," International Journal of Clinical Practice, vol. 60, no. 8, pp. 959-966, 2006.

Chapple CR, Fianu-Jonsson A, Indig M, et al; STAR study group. Treatment outcomes in the STAR study: a subanalysis of solifenacin $5 \mathrm{mg}$ and tolterodine ER $4 \mathrm{mg}$. Eur Urol 2007;52:1195-1203.

Chapple CR, Yamaguchi O, Ridder A, et al. Clinical proof of concept study (Blossom) shows novel $\beta 3$ adrenoceptor agonist YM178 is effective and well tolerated in the treatment of symptoms of overactive bladder. Eur Urol Suppl 2008.

Chancellor MB, Kianifard F, Beamer E, et al. A comparison of the efficacy of darifenacin alone vs. darifenacin plus a Behavioural Modification Programme upon the symptoms of overactive bladder. Int J Clin Pract 2008;62:606-613.

Choo MS, Doo CK, Lee KS. Satisfaction with tolterodine: assessing symptom-specific patient-reported goal achievement in the treatment of overactive bladder in female patients (STARGATE study)," International Journal of Clinical Practice, vol. 62, no. 2, pp. 191-196, 2008. 
Colli E, Digesu GA, Olivieri L. Overactive bladder treatments in early phase clinical trials. Expert Opin Investig Drugs 2007;16:999-1007.

Coyne KS, Zyczynski T, Margolis MK, et al. Validation of an overactive bladder awareness tool for use in primary care settings. Adv Ther 2005;22:381-394.

Coyne KS, Matza LS, Thompson CL. The responsiveness of the overactive bladder questionnaire (OAB-Q). Qual Life Res 2005;14:849-855.

Davila GW, Daugherty CA, Sanders SW, Transdermal Oxybutynin Study Group. A shortterm, multicenter, randomized double-blind dose titration study of the efficacy and anticholinergic side effects of transdermal compared to immediate release oral oxybutynin treatment of patients with urge urinary incontinence. J Urol 2001; 166:140.

de Nunzio, C., et al., The evolution of detrusor overactivity after watchful waiting, medical therapy and surgery in patients with bladder outlet obstruction. J Urol, 2003. 169(2): p. 535-9.

de Groat, W.C., A.M. Booth, and N. Yoshimura, Neurophysiology of micturition and its modeification in animal models of human disease, in The Autonomic Nervous System:Nervous Control of the Urogenital System, C.A. Maggi, Editor. 1993, Harwood Academic Publishers: London. p.27-290.

de Groat WC, Yoshimura N. Pharmacology of the lower urinary tract. Annu Rev Pharmacol Toxicol 2001;41:691-721.

de Groat WC. The urothelium in overactive bladder: passive bystander or active participant? Urology 2004;64(6 suppl 1):7-11.

Dmochowski RR, Davila GW, Zinner NR, et al. Efficacy and safety of transdermal oxybutynin in patients with urge and mixed urinary incontinence. J Urol 2002; 168:580.

Dmochowski RR, Sand PK, Zinner NR, Staskin DR. Trospium 60 mg once daily (QD) for overactive bladder syndrome: results from a placebo-controlled interventional study. Urology 2008; 71:449.

DuBeau CE. (2011). Treatment of urinary incontinence, In: UpToDate, accessed 8/18/2011, Available from: http://www.uptodate.com/contents/treatment-of-urinaryincontinence? source $=$ search_result\&selectedTitle $=1 \% 7 \mathrm{E} 81 \mathrm{\# H}$

Duthie J, Wilson DI, Herbison GP, et al. Botulinum toxin injections for adults with overactive bladder syndrome. Cochrane Database Syst Rev 2007;3:CD005493.

Elbadawi A, Yalla SV, Resnick NM. Structural basis of geriatric voiding dysfunction. II. Aging detrusor: normal versus impaired contractility. J Urol, 1993. 150(5 Pt 2): p.1657-67.

Elbadawi A, Yalla SV, Resnick NM. Structural basis of geriatric voiding dysfunction. III. Detrusor overactivity. J Urol, 1993. 150(5 Pt 2): p. 1668-80.

Elbadawi A, Yalla SV, Resnick NM.. Structural basis of geriatric voiding dysfunction. IV. Bladder outlet obstruction. J Urol, 1993. 150(5 Pt 2): p. 1681-95.

Eriksen PS, Rasmussen H. Low-dose 17 beta-estradiol vaginal tablets in the treatment of atrophic vaginitis: a doubleblind placebo controlled study. Eur J Obstet Gynecol Reprod Biol, 1992. 44(2): p. 137-44.

Fall, M., B.L. Ohlsson, and C.A. Carlsson, The neurogenic overactive bladder. Classification based on urodynamics. Br J Urol, 1989. 64(4): p. 368-73.

Fall M, Lindstrom S, Electrical stimulation: a physiologic approach to the treatment of urinary incontinence, Urologic Clinics of North America, vol. 18, no. 2, pp. 393-407, 1991. 
Fall, M., G. Geirsson, and S. Lindstrom, Toward a new classification of overactive bladders. Neurourol Urodyn, 1995. 14(6): p. 635-46.

Fantl JA, Newman DK, Colling J, et al. Urinary Incontinence in Adults: Acute and Chronic Management, Clinical

Practice Guideline no. 2, Agency for Health Care Policy and Research, Rockville,Md, USA, 1996, AHCPR publication no. 96-0682.

Ferguson DR, Kennedy I, Burton TJ. ATP is released from rabbit urinary bladder epithelial cells by hydrostatic pressure changes - a possible sensory mechanism? J Physiol, 1997. 505 ( Pt 2): p. 503-11.

Foote J, Glavind K, Kralidis G, Wyndaele JJ. Treatment of overactive bladder in the older patient: pooled analysis of three phase III studies of darifenacin, an M3 selective receptor antagonist," European Urology, vol. 48, no. 3, pp. 471-477, 2005.

Fowler CJ, Griffiths D, de Groat WC. The neural control of micturition. Nat Rev Neurosci 2008; 9:453.

Glazener CM, Evans JH, Peto RE. Tricyclic and related drugs for nocturnal enuresis in children. Cochrane Database Syst Rev 2003;3:CD002117.

Goode PS, Burgio KL, Locher JL, et al. Effect of behavioral training with or without pelvic floor electrical stimulation on stress incontinence in women: a randomized controlled trial. JAMA 2003; 290:345.

Gormley EA. Biofeedback and behavioral therapy for the management of female urinary incontinence," Urologic

Clinics of North America, vol. 29, no. 3, pp. 551-557, 2002.

Green SA, Alon A, Ianus J, et al. Efficacy and safety of a neurokinin-1 receptor antagonist in postmenopausal women with overactive bladder with urge urinary incontinence. J Urol 2006;176:2535-2540.

Greenland JE,Brading AF. The effect of bladder outflow obstruction on detrusor blood flow changes during the voiding cycle in conscious pigs. J Urol, 2001. 165(1): p.245-8

Griffiths AN, Makam A, Edwards GJ. Should we actively screen for urinary and anal incontinence in the general gynaecology outpatients setting? - a prospective observational study. J Obstet Gynaecol 2006;26:442-444.

Griffiths D, Tadic SD, Schaefer W, Resnick NM. Cerebral control of the bladder in normal and urge-incontinent women. Neuroimage 2007; 37:1.

Grond S, Sablotzki A. Clinical pharmacology of tramadol. Clin Pharmacokinet 2004;43:879_ 923.

Haab F, Corcos J, Siami P, et al. Long-termtreatment with darifenacin for overactive bladder: results of a 2-year, open label extension study," BJU International, vol. 98, no. 5, pp. 1025-1032, 2006.

Harrison, S.C., et al., Bladder instability and denervation in patients with bladder outflow obstruction. Br J Urol, 1987. 60(6): p. 519-22.

Harris SS, Link CL, Tennstedt SL, et al. Care seeking and treatment for urinary incontinence in a diverse population. J Urol 2007;177:680-684.

Hay-Smith J, Herbison P, Ellis G, et al. Which anticholinergic drug for overactive bladder symptoms in adults. Cochrane Database Syst Rev 2005;3:CD005429.

Hay-Smith, J, Berghmans, BK, et al. Adult conservative management. In: Abrams, P, Cardozo, L, Khoury, S, Wein, A. Paris: Editions 21, for Health Publications Ltd, 2009; p.1025. 
Hill S, Elhilali M, Millard RJ, et al. Long-term darifenacin treatment for overactive bladder in patients aged 65 years and older: analysis of results from a 2-year, open-label extension study. Current Medical Research and Opinion, vol.23, no. 11, pp. 26972704, 2007.

Homma Y. The clinical significance of the urodynamic investigation in incontinence. BJU Int 2002;90:489-497.

Hosker G, Rosier P, Gajewski J, Sand P, Szabo L, Capewell A. Dynamic testing. In:Abrams P, Cardozo L, Khoury S, Wein A. Incontinence. Health Publication Ltd 2009 Paris France.

Hughes KM, Lang JCT, Lazare R, et al. Measurement of oxybutynin and its N-desethyl metabolite in plasma, and its application to pharmacokinetic studies in young, elderly and frail elderly volunteers," Xenobiotica, vol. 22, no. 7, pp. 859-869, 1992.

Hunsballe JM, Djurhuus JC. Clinical options for imipramine in the management of urinary incontinence. Urol Res 2001;29:118-125.

International Continence Society. Available at www.ics.org. Accessed 10/14/2011.

Irwin DE, Milsom I, Hunskaar S, et al. Population-based survey of urinary incontinence, overactive bladder, and other lower urinary tract symptoms in five countries: results of the EPIC study. Eur Urol 2006;50:1306-1315.

Irwin DE, Milsom I, Kopp Z, et al. Impact of overactive bladder symptoms on employment, social interactions and emotional well-being in six European countries. BJU Int 2006;97:96-100.

Ishizuka O, Igawa Y, Lecci A, et al. Role of intrathecal tachykinins for micturition in unanaesthetized rats with and without bladder outlet obstruction. Br J Pharmacol 1994;113:111-116.

Janknegt RA, Hassouna MM, Siegel SW, et al. Long-term effectiveness of sacral nerve stimulation for refractory urge incontinence. Eur Urol 2001;39:101-106.

Kay G, Crook T, Rekeda L, et al. Differential effects of the antimuscarinic agents darifenacin and oxybutynin ER on memory in older subjects. European Urology, vol. 50, no. 2, pp. 317-326, 2006.

Khastgir J, Hamid R, Arya M, Shah N, Shah PJ: Surgical and patient reported outcomes of 'clam' augmentation ileocystoplasty in spinal cord injured patients. Eur Urol 2003, 43(3):263-269.

Koelbl H, Nitti V, Baessler K, Salvatore S, Sultan A, Yamaguchi O. Pathophysiology of Urinary Incontinence,

Faecal Incontinence and Pelvic Organ Prolapse. In:Abrams P, Cardozo L, Khoury S, Wein A. Incontinence Health Publication Ltd 2009 Paris France.

Leong RK, De Wachter SGG, Van Kerrebroeck,PEV. Current information on sacral neuromodulation and

botulinumtoxin treatment for refractory idiopathic overactive bladder syndrome: a review, Urologia Internationalis, vol. 84, no. 3, pp. 245-253, 2010.

Mansfiel, KJ et al., Muscarinic receptor subtypes in human bladder detrusor and mucosa, studied by radioligand

binding and quantitative competitive RT-PCR: changes in ageing. Br J Pharmacol, 2005. 144(8): p. 1089-99.

Mardon RE, Halim S, Pawlson LG, et al. Management of urinary incontinence in Medicare managed care beneficiaries: results from the 2004 Medicare Health Outcomes Survey. Arch Intern Med 2006;166:1128-1133. 
Mattiasson A, Blaakaer J, Høye K, et al. Simplified bladder training augments the effectiveness of tolterodine in patients with an overactive bladder. BJU Int. 2003;91:54-60.

McGrother CW, Donaldson MM, Hayward T, et al; Leicestershire MRC Incontinence Study Team. Urinary storage symptoms and comorbidities: a prospective population cohort study in middle-aged and older women. Age Ageing 2006;35:16-24.

Mills IW et al., Studies of the pathophysiology of idiopathic detrusor instability: the physiological properties of the detrusor smooth muscle and its pattern of innervation. J Urol, 2000. 163(2): p. 646-51.

Milne JL and Moore KN. Factors impacting self-care for urinary incontinence," Urologic Nursing, vol. 26, no. 1, pp. 41-51, 2006.

Milne JL. Behavioral therapies for overactive bladder: making sense of the evidence. Journal of Wound, Ostomy and Continence Nursing, vol. 35, no. 1, pp. 93-101, 2008.

Milsom I, Abrams P, Cardozo L, et al. How widespread are the symptoms of an overactive bladder and how are they managed? A population-based prevalence study. BJU Int 2001;87:760-766.

Nilvebrant L, Sparf B. Dicyclomine, benzhexol, and oxybutynine distinguish between subclasses of muscarinic binding sites. European Journal of Pharmacology, vol. 123, no. 1, pp. 133-143, 1986.

Nixon A, Colman S, Sabounjian L, et al. A validated patient reported measure of urinary urgency severity in overactive bladder for use in clinical trials. J Urol 2005;174:604607.

Nygaard IE, Kreder KJ, Lepic MM, Fountain KA, Rhomberg AT. Efficacy of pelvic floor muscle exercises in women with stress, urge, and mixed urinary incontinence. American Journal of Obstetrics and Gynecology, vol. 174, no. 1, part 1, pp. 120-125, 1996.

Ouslander JG, Ai-Samarrai N, Schnelle JF. Prompted voiding for nighttime incontinence in nursing homes: is it effective? J Am Geriatr Soc 2001;49:706-709.

Peters KM, Macdiarmid SA, Wooldridge LS, et al. Randomized trial of percutaneous tibial nerve stimulation versus extended-release tolterodine: results from the overactive bladder innovative therapy trial. J Urol 2009;182:1055-1061. Reitz A, Denys P, Fermanian C, et al. Do repeat intradetrusor botulinum toxin type A injections yield valuable results? Clinical and urodynamic results after five injections in patients with neurogenic detrusor overactivity. Eur Urol 2007;52:1729-1735.

Safarinejad MR, Hosseini SY. Safety and efficacy of tramadol in the treatment of idiopathic detrusor overactivity: a double-blind, placebo-controlled, randomized study. Br J Clin Pharmacol 2006;61:456-463.

Schafer W et al., Good urodynamic practices: uroflowmetry, filling cystometry, and pressure-flow studies. Neurourol Urodyn, 2002. 21(3): p. 261-74.

Schurch B, Denys P, Kozma CM, et al. Botulinum toxin A improves the quality of life of patients with neurogenic urinary incontinence. Eur Urol 2007;52:850-858.

Shaw HA, Burrows LJ. Etilogy and treatment of overactive bladder in women. South Med J. 2011 Jan;104(1):34-9. Review.

Staskin D, Sand P, Zinner N, Dmochowski R. Once daily trospium chloride is effective and well tolerated for the treatment of overactive bladder: results from a multicenter phase III trial. Journal of Urology, vol. 178, no. 3, pp. 978-984, 2007. 
Steers WD, Herschorn S, Kreder KJ, et al; Duloxetine OAB Study Group. Duloxetine compared with placebo for treating women with symptoms of overactive bladder. BJU Int 2007;100:337-345.

Stewart WF, Van Rooyen JB, Cundiff GW, et al. Prevalence and burden of overactive bladder in the United States. World J Urol 2003;20:327-336.

Subak LL, Wing R, West DS, et al. Weight loss to treat urinary incontinence in overweight and obese women. N Engl J Med 2009; 360:481.

Swithinbank L, Hashim H, and Abrams P, "The effect of fluid intake on urinary symptoms in women," Journal of Urology, vol. 174, no. 1, pp. 187-189, 2005.

Van Der Pal F, Heesakkers JPFA, Bemelmans BLH. Current opinion on the working mechanisms of neuromodulation in the treatment of lower urinary tract dysfunction, Current Opinion in Urology, vol. 16, no. 4, pp. 261-267, 2006.

van Kerrebroeck PE, van Voskuilen AC, Heesakkers JP, et al. Results of sacral neuromodulation therapy for urinary voiding dysfunction: outcomes of a prospective, worldwide clinical study. J Urol 2007;178:2029-2034.

Versi E, Appell R, Mobley D, et al. Dry mouth with conventional and controlled-release oxybutynin in urinary incontinence. The Ditropan XL Study Group. Obstet Gynecol 2000; 95:718.

Vodusek, DB, Light JK, Libby JM. Detrusor inhibition induced by stimulation of pudendal nerve afferents. Neurourology and Urodynamics, vol. 5, no. 4, pp. 381-389, 1986.

Wagg AS, Cardozo L, Chapple C, et al. Overactive bladder syndrome in older people. BJU Int 2007;99:502-509.

Wallace SA, Roe B, Williams K, Palmer M. Bladder training for urinary incontinence in adults. Cochrane Database of Systematic Reviews 2004, Issue 1. Art. No.: CD001308. DOI: 10.1002/14651858.CD001308.pub2

Wein AJ. Pathophysiology and categorization of voiding dysfunction, in Walsh P, Retik A, Vaughan ED Jr, et al (eds): Campbell's Urology. Philadelphia, Saunders, 2002, ed 8, pp 887.

Wilson PD, Berghmans B, Hagen S, et al. Adult conservative management, in Abrams P, Cardozo L, Khoury S, et al (eds): Incontinence Management. Paris, Health Publications, 2005, pp 855-894.

Wyman JF, Fantl JA, McClish DK, Bump RC. Comparative efficacy of behavioral interventions in themanagement of female urinary incontinence. American Journal of Obstetrics and Gynecology, vol. 179, no. 4, pp. 999-1007, 1998.

Yoong W, Ridout AE, Damodaram M, Dadswell R. Neuromodulative treatment with percutaneous tibial nerve stimulation for intractable detrusor instability: outcomes following a shortened 6-week protocol, BJU International, vol. 106, no. 11, pp. 16731676, 2010.

Zinner N, Gittelman M, Harris R, et al. Trospium chloride improves overactive bladder symptoms: a multicenter phase III trial. J Urol 2004; 171:2311.

Zinner N, Susset J, Gittelman M, et al. Efficacy, tolerability and safety of darifenacin, an M(3) selective receptor antagonist: an investigation of warning time in patients with OAB. Int J Clin Pract 2006; 60:119.

Zinner N, Kobashi KC, Ebinger U, et al. Darifenacin treatment for overactive bladder in patients who expressed dissatisfaction with prior extended-release antimuscarinic therapy," International Journal of Clinical Practice, vol. 62, no.11, pp. 1664-1674, 2008. 


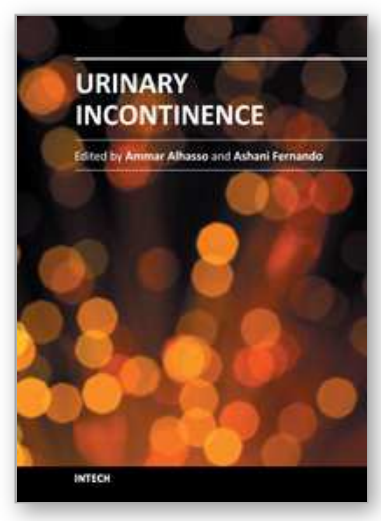

\author{
Urinary Incontinence \\ Edited by Mr. Ammar Alhasso
}

ISBN 978-953-51-0484-1

Hard cover, 324 pages

Publisher InTech

Published online 04, April, 2012

Published in print edition April, 2012

Management strategies are framed within a multidisciplinary team structure and as such a range of specialists ranging from psychologists, specialist nurses, gynaecologists and urologists author the chapters. There are some novel methods outlined by the authors with their clinical application and utility described in detail, along with exhaustive research on epidemiology, which is particularly relevant in planning for the future.

\title{
How to reference
}

In order to correctly reference this scholarly work, feel free to copy and paste the following:

Howard A. Shaw and Julia A. Shaw (2012). Diagnosis and Treatment of Overactive Bladder, Urinary Incontinence, Mr. Ammar Alhasso (Ed.), ISBN: 978-953-51-0484-1, InTech, Available from: http://www.intechopen.com/books/urinary-incontinence/diagnosis-and-treatment-of-overactive-bladder

\section{INTECH}

open science | open minds

\section{InTech Europe}

University Campus STeP Ri

Slavka Krautzeka 83/A

51000 Rijeka, Croatia

Phone: +385 (51) 770447

Fax: +385 (51) 686166

www.intechopen.com

\section{InTech China}

Unit 405, Office Block, Hotel Equatorial Shanghai

No.65, Yan An Road (West), Shanghai, 200040, China 中国上海市延安西路65号上海国际贵都大饭店办公楼 405 单元

Phone: +86-21-62489820

Fax: $+86-21-62489821$ 
(C) 2012 The Author(s). Licensee IntechOpen. This is an open access article distributed under the terms of the Creative Commons Attribution 3.0 License, which permits unrestricted use, distribution, and reproduction in any medium, provided the original work is properly cited. 